\title{
Predictors for multiple hospital admissions in children with asthma
}

\author{
Fuat Gürkan MD, Aydin Ece MD, Kenan Haspolat MD \\ Orhan Derman MD, Mehmet Bosnak MD \\ Dicle University Hospital, Department of Pediatrics, Diyarbakir, Turkey
}

F Gürkan, A Ece, K Haspolat, O Derman, M Bosnak. Predictors for multiple hospital admissions in children with asthma. Can Respir J 2000;7(2):163-166.

BACKGROUND: Asthma is one of the most frequent causes of preventable hospital admissions among children. OBJECTIVES: To identify preventable risk factors for future hospital admissions. Some of the environmental and patient characteristics of children who were hospitalized more than once with an acute asthma attack were investigated.

DESIGN, SETTING AND PATIENTS: An analysis was performed of 140 children with asthma, aged three to 15 years, admitted to the Department of Pediatrics at Dicle University Hospital, Diyarbakir, Turkey, over three years, followed for a maximum of 48 months. Associations between hospital admissions and probable predictors (clinical findings, laboratory studies and a detailed case history) were analyzed.

RESULTS: The asthma admissions were higher in boys than in girls (male to female ratio 1.86). Of 140 children, 30 $(21.4 \%)$ had multiple admissions, defined as a mean of more than one admission per year during the follow-up period. The following factors were associated significantly with the frequency of hospital admission for asthma attacks when analyzed using a $\chi^{2}$ test: indoor cigarette smoking (odds ratio [OR] 2.55), maternal smoking (OR 4.05), symptoms of dermal atopy (OR 2.96), symptoms of allergic conjunctivitis (OR 2.68), age less than five years (OR 5.12) and use of inhaled corticosteroids during the follow-up (OR 0.37). With multivariate logistic regression analysis, among other factors, only maternal smoking $(\mathrm{r}=0.29, \mathrm{P}=0.017)$ and age less than five years $(\mathrm{r}=-0.32, \mathrm{P}=0.012)$ were significant effective factors for the multiple hospital admissions. No significant association with the frequency of hospital admission was found for sex, serum total immunoglobulin E, history of frequent upper respiratory tract infections or number of family members. CONCLUSIONS: Prevention of indoor smoking, especially maternal smoking, may be effective in decreasing hospital admissions in children with asthma. Children less than five years of age are more likely to be hospitalized than are children five years of age or greater.

Key Words: Asthma; Atopy; Children; Cigarette exposure; Hospital admissions; Respiratory infection

voir page suivante

This paper was presented in part at the Joint meeting of the European Respiratory Society Paediatric Assembly and the European Society of Paediatric Allergy and Clinical Immunology in Berlin, Germany, May 26 to 29, 1999

Correspondence: Dr Fuat Gürkan, Dicle Universitesi Hastanesi, Çocuk Servisi, Diyarbakir, Turkey

Telephone +90412 2488074, fax+90412 2488440, e-mail fuatgurkan@hotmail.com 


\section{Prédicteurs d'hospitalisations à répétition chez les enfants asthmatiques}

CONTEXTE : L'asthme est l'une des causes les plus fréquentes d'hospitalisations évitables chez les enfants.

OBJECTIF : Cerner les facteurs de risque évitables de futures hospitalisations. Certaines particularités environnementales et personnelles ont fait l'objet d'analyse chez des enfants qui ont été hospitalisés plus d'une fois pour des crises d'asthme.

PLAN D'ÉTUDE, LIEU ET PATIENTS : On a étudié le cas de 140 enfants asthmatiques, âgés de 3 à 15 ans, admis au service de pédiatrie du Dicle University Hospital, à Diyarbakir, en Turquie, sur une période de trois ans et suivis pendant 48 mois au maximum. Les chercheurs se sont intéressés aux liens entre les hospitalisations et différents prédicteurs probables (observations cliniques, examens de laboratoire, anamnèses détaillées).

RESULTATS : Les hospitalisations pour crises d'asthme étaient plus fréquentes chez les garçons que chez les filles (rapport garçons/filles : 1,86). Des 140 enfants à l'étude, 30 $(21,4 \%)$ comptaient des hospitalisations à répétition, définies comme une moyenne de plus d'une hospitalisation par année durant la période de suivi. Les facteurs suivants ont été associés de façon appréciable à la fréquence des hospitalisations pour crises d'asthme dans les analyses faites à partir du test du chi carré : fumée de cigarette à l'intérieur (risque relatif approché [RRA] : 2,55), tabagisme chez la mère (RRA : 4,05), symptômes d'atopie dermique (RRA : 2,96), symptômes de conjonctive allergique (RRA : 2,68), bas âge (moins de cinq ans) (RRA : 5,12) et utilisation de corticostéroïdes par inhalation durant le suivi (RRA : 0,37). Dans l'analyse de régression logistique à plusieurs variables, seuls le tabagisme chez la mère $(\mathrm{r}=0,29, \mathrm{P}=0,017)$ et le fait d'être en bas âge (moins de cinq ans) ( $\mathrm{r}=-0,32, \mathrm{P}=0,012)$ se sont révélés des facteurs significatifs d'hospitalisations à répétition. Aucun lien important n'a été établi entre la fréquence des hospitalisations et le sexe, la concentration sérique totale d'immunoglobines $\mathrm{E}$, les antécédents d'infections fréquentes des voies respiratoires supérieures et le nombre de membres dans la famille.

CONCLUSIONS : La prévention de la fumée de cigarette à l'intérieur, surtout le tabagisme chez la mère, peut s'avérer une mesure efficace pour diminuer le nombre d'hospitalisations chez les enfants asthmatiques. Les enfants de moins de cinq ans sont plus susceptibles d'être hospitalisés que les enfants de cinq ans ou plus.
A sthma remains one of the most common causes of hospitalization in children. Although many countries have reported a decline in mortality with the development of effective asthma therapy, there is an increase in morbidity, particularly hospitalizations, with the rising prevalence of asthma in recent years $(1,2)$. Hospital admission rates for asthma may be higher in some patients because of differences in the uptake or delivery of preventive health care strategies. Furthermore, the extent to which patient characteristics contribute to hospitalization needs to be determined. The present study describes the sociodemographic, clinical and laboratory characteristics of children who were hospitalized on several occasions with an acute asthma attack, and identifies factors that may have contributed to hospital admissions, in the hope of preventing future admissions.

\section{PATIENTS AND METHODS}

In January 1999, the medical records of pediatric patients first admitted for asthma to the Pediatrics Clinic of Dicle University Hospital in the Diyarbakir region of Turkey (total population 1,200,000), between January 1995 and December 1997 were reviewed. The hospital has an emergency room service for children with asthma who were first admitted to, or referred from, other hospitals in the region. There were no changes in the number of beds in the hospital during the study period.

Clinical findings and laboratory studies recorded by physicians and a detailed case history obtained from parents at the time of the first admission were carefully evaluated. Any patient with missing medical records or who was dropped from follow-up was removed from the study, leaving 140 patients. Multiple admissions were defined as a mean of more than one admission per year during the follow-up period until January 1999, and others were considered as single admissions. The follow-up period ranged from 13 months for patients admitted in December 1997 to a maximum of 48 months for patients admitted in January 1995. The factors contributing to multiple admissions as opposed to single admissions to hospital for acute asthma were investigated. These contributing factors included sex, current age and age at onset of asthma symptoms, symptoms of other allergic diseases (allergic rhinoconjunctivitis, atopic dermatitis), serum total immunoglobulin E, frequency of previous upper respiratory tract infections, nutritional status with breast and cow's milk consumption at infancy, number and history of atopy, smoking habits of family members and place of residence. Only patients admitted principally because of asthma were considered. Patients with asthma were excluded if they suffered from concurrent medical illnesses for which they were seeking medical advice or being treated.

Associations between hospital admissions and the above predictors were analyzed using an unpaired $t$ test and $\chi^{2}$ test. Multivariate logistic regression analysis was performed to examine the simultaneous effects of the variables. $\mathrm{P}<0.05$ was considered significant.

\section{RESULTS}

Bronchial asthma was more predominant in boys than in girls (male to female ratio 1.86). The ages of all children ranged between three and 15 years, with a mean of $6.2 \pm 3.4$ years and median of 6.0 years. Of 140 children, 30 had multiple admissions, while the others had a single admission. More frequent hospitalizations in children aging less than five years were observed than in older children (Table 1).

With the $\chi^{2}$ test, the following factors were significantly associated with the frequency of hospital admission for asthma attacks: indoor cigarette smoking $(\mathrm{P}=0.04)$, maternal smoking $(\mathrm{P}=0.02)$, symptoms of dermal atopy $(\mathrm{P}=0.03)$, 
TABLE 1

Number of children with and/or without each variable found within multiply hospitalized and other patients with asthma

\begin{tabular}{|c|c|c|c|c|c|c|}
\hline & \multicolumn{2}{|c|}{ Multiple hospitalizations $(n=30)$} & \multicolumn{2}{|c|}{ Other $(n=110)$} & \multirow[b]{2}{*}{ OR $(95 \% \mathrm{Cl})$} & \multirow[b]{2}{*}{$\mathbf{P}$} \\
\hline & $\mathbf{n}$ & $\%$ & $\mathbf{n}$ & $\%$ & & \\
\hline Age five years or lower & 23 & 76.7 & 43 & 39.1 & $5.12(2.02-12.95)$ & 0.02 \\
\hline Allergic conjunctivitis & 20 & 66.6 & 47 & 42.7 & $2.68(1.15-6.26)$ & 0.04 \\
\hline Eczema in child & 11 & 36.6 & 18 & 16.4 & $2.96(1.20-7.25)$ & 0.03 \\
\hline Frequent URI & 26 & 86.7 & 86 & 78.2 & $1.8(0.57-5.71)$ & 0.44 \\
\hline Maternal smoking & 7 & 23.3 & 8 & 7.2 & $4.05(1.47-11.78)$ & 0.02 \\
\hline Familial allergy & 18 & 60.0 & 59 & 53.6 & $1.29(0.57-2.95)$ & 0.60 \\
\hline Positive prick test & 23 & 76.7 & 72 & 65.4 & $1.73(0.68-4.41)$ & 0.34 \\
\hline High serum total IgE & 22 & 73.3 & 79 & 71.8 & $1.45(0.59-3.57)$ & 0.94 \\
\hline Urban residency & 24 & 80.0 & 89 & 80.9 & $0.94(0.34-2.59)$ & 0.90 \\
\hline
\end{tabular}

IgE Immunoglobulin E; URI Upper respiratory tract infection

TABLE 2

Some variables in multiply hospitalized and other asthmatic children (mean \pm SD)

\begin{tabular}{lccc}
\hline & $\begin{array}{c}\text { Multiple hospitalizations } \\
(\mathbf{n}=\mathbf{3 0})\end{array}$ & $\begin{array}{c}\text { Others } \\
(\mathbf{n}=\mathbf{1 1 0})\end{array}$ & $\mathbf{P}$ \\
\hline Age of child (years) & $4.8 \pm 3.5$ & $6.4 \pm 3.7$ & 0.04 \\
Total IgE (GM \pm SEM, kIU/L) & $316 \pm 90$ & $245 \pm 87$ & $\mathrm{NS}$ \\
Duration of breast feeding (months) & $11.2 \pm 7.7$ & $10.8 \pm 6.3$ & $\mathrm{NS}$ \\
Introduction with cow's milk (months) & $6.4 \pm 4.6$ & $7.4 \pm 6.1$ & $\mathrm{NS}$ \\
Eosinophils in peripheral smear (\%) & $5.3 \pm 3.7$ & $3.7 \pm 3.6$ & 0.03 \\
Eosinophils in nasal smear (\%) & $21.1 \pm 28.1$ & $18.1 \pm 21.1$ & $\mathrm{NS}$ \\
Age at asthma onset (years) & $3.2 \pm 3.1$ & $2.0 \pm 2.2$ & 0.03 \\
Number of households & $5.4 \pm 2.1$ & $5.8 \pm 2.06$ & $\mathrm{NS}$
\end{tabular}

GM Geometric mean; IgE Immunoglobulin E; NS Not significant; SEM Standard error

symptoms of allergic conjunctivitis $(\mathrm{P}=0.04)$, age less than five years $(\mathrm{P}=0.02)$ and use of inhaled corticosteroids during the follow-up $(\mathrm{P}=0.03)$. No significant association with the frequency of hospital admission was found for sex, serum total immunoglobulin E, history of frequent upper respiratory tract infections, number of family members, duration of breastfeeding, age of month to start feeding with cow's milk, family history of atopy and rural or urban residency.

The number of children receiving any asthma drugs in the $24 \mathrm{~h}$ before the first admission to hospital did not differ significantly according to number of hospitalizations $(\mathrm{P}>0.05$, data not shown). With multivariate logistic regression analysis, among other factors, only maternal smoking ( $\mathrm{r}=0.19$, OR 3.25 [95\% CI 1.13 to 8.85 ], $\mathrm{P}=0.017$ ) and age less than five years ( $\mathrm{r}=0.22$, OR 3.96 [95\% CI 1.09 to 9.78], $\mathrm{P}=0.012$ ) were found to be significant factors affecting the multiple hospital admissions. Patient characteristics of multiply hospitalized patients are compared with those of the rest of the patients in Tables 1 and 2 .

\section{DISCUSSION}

Admissions to hospitals for childhood asthma seem to be increasing, even though admissions for other childhood conditions are decreasing. Furthermore, readmission to hospital for asthma is very frequent. In all readmissions of childhood diseases, $73.2 \%$ have been reported to be for asthma (3). Evaluating the regional causes of these hospital readmissions can provide useful insights concerning patterns in the incidence and medical care for acute asthma in children.

In the present study, we found that $21.4 \%$ of 140 children admitted to the hospital for asthma during a selected period were hospitalized multiple times. The hospital admission rate for the children with asthma is expected to be greater in boys than girls, given the male predominance for the incidence of the disease. However, excess asthma hospitalization was demonstrated in both sexes and all age groups. Although there was no change in hospital admissions in our study population according to sex at any age, the results were different in some other studies. The rates of hospital admission for asthma among boys aged less than 15 years of age were reported to be higher than those among girls of the same age (4). In a study by Senthilselvan (5), girls aged 10 to 14 years were reported to have higher hospital readmission rates for asthma than boys of the same age, for unknown reasons.

Asthma hospitalization rates were particularly striking among children below the age of five years in the present study. The occurrences of new asthma admissions were found to be most frequent at the age of one year (5.3 in 1000 
for boys and 2.9 in 1000 for girls) in a previous large-scale study of asthma-related hospital admissions comprising patients of all ages (6). The six-month probabilities of readmission for asthma were $20.0 \%$ for children zero to four years of age and $11.7 \%$ for children aged five to 17 years in another study (3). The declining admission rates in a study population in Canada were largely related to the lower admission rates among school-aged children aged five to 17 years. The relatively high admission and readmission rates of preschool children $(3,7)$, as found in the present study, are still thought to be a concern that needs further research to examine the contributing factors.

Exposure to environmental tobacco smoke more than doubles the risk of asthma in young children and increases the risk of hospitalization in children with asthma (8). Our study suggests that the prevention of indoor smoking, especially maternal smoking, may be effective in decreasing hospital admissions in children with asthma, as supported by previous studies. Burr et al (9) reported that children who lived with a smoker were more likely than others to have wheezed in the past year. In the study of Mitchell and Burr (10), the number of parents who smoked in the home was found to be related to asthma admissions, with no difference seen between multiple and single admission groups. In the study of Huss et al (11), parental smoking and overcrowding of bedrooms were reported to be risk factors of asthma recurrence in early childhood, while age at the onset of symptoms, positive familial medical history for allergic illness, breast feeding and atopic dermatitis were not predictive. In the elderly, hospital admission rates for asthma were shown to be particularly associated with cigarette smoking (12). As well as indoor air pollution by cigarette smoking, outdoor air pollution, especially nitrogen dioxide levels in the ward of residence, were also found to be significantly associated with standardized hospital admission rates for all respiratory disease in children under five years of age (13).

Various factors, such as admission criteria, medical management and/or clinical expression of the disease were not taken into account in our study because no radical changes in these criteria occurred in our department during the study period. It was suggested in a recent study that there was no association between pretreatment assessments for disease severity and hospitalization (14).

\section{CONCLUSIONS}

Patients younger than five years of age appeared to be at high risk for multiple hospitalizations. Moreover, tobacco smoke, particularly maternal smoking, was found to be one of the correlates influencing the rate of hospitalization. Clinicians should be aware that children with asthma at earlier ages are subject to frequent hospitalizations for the disease and should supply a clear individualized plan for follow-up of these children. There is also an obvious need for increasing educational efforts to alter parental smoking habits.

\section{REFERENCES}

1. Anderson HR, Butland BK, Strachan DP. Trends in prevalence and severity of childhood asthma. BMJ 1994;308:1600-4.

2. Peat JK, van den Berg RH, Green WF, Mellis CM, Leeder SR, Woolcock AJ. Changing prevalence of asthma in Australian children. BMJ 1994;308:1591-6.

3. To T, Dick P, Feldman W, Hernandez R. A cohort study on childhood asthma admissions and readmissions. Pediatrics 1996;98:191-5.

4. Wilkins K, Mao Y. Trends in rates of admission to hospital and death from asthma among children and young adults in Canada during the 1980s. CMAJ 1993;148:185-90.

5. Senthilselvan A. Effect of readmissions on increasing hospital admissions for asthma in children. Thorax 1995;50:934-6.

6. Harju T, Keistinen T, Tuuponen T, Kivela SL. Hospital admissions of asthmatics by age and sex. Allergy 1996;51:693-6.

7. Farber HJ. Risk of readmission to hospital for pediatric asthma. J Asthma 1998;35:95-9.

8. Martinez FD, Cline M, Burrows B. Increased incidence of asthma in children of smoking mothers. Pediatrics 1992;89:21-6.

9. Burr ML, Verrall C, Kaur B. Social deprivation and asthma. Respir Med 1997;91:603-8.

10. Mitchell EA, Burr D. Comparison of the characteristics of children with multiple admissions to hospital for asthma with those with a single admission. N Z Med J 1987;100:736-8.

11. Huss K, Rand CS, Butz AM, et al. Home environmental risk factors in urban minority asthmatic children. Ann Allergy 1994;72:173-7.

12. Morris RD, Munasinghe RL. Geographic variability in hospital admission rates for respiratory disease among the elderly in the United States. Chest 1994;106:1172-81.

13. Walters S, Phupinyokul M, Ayres J. Hospital admission rates for asthma and respiratory disease in the West Midlands: their relationship to air pollution levels. Thorax 1995;50:948-54.

14. Schuh S, Johnson D, Stephens D, Callahan S, Canny G. Hospitalization patterns in severe acute asthma in children. Pediatr Pulmonol 1997;23:184-92. 


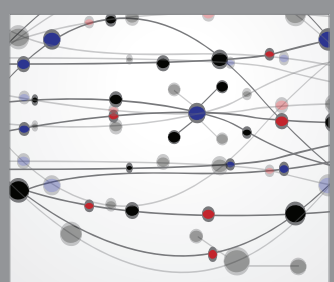

The Scientific World Journal
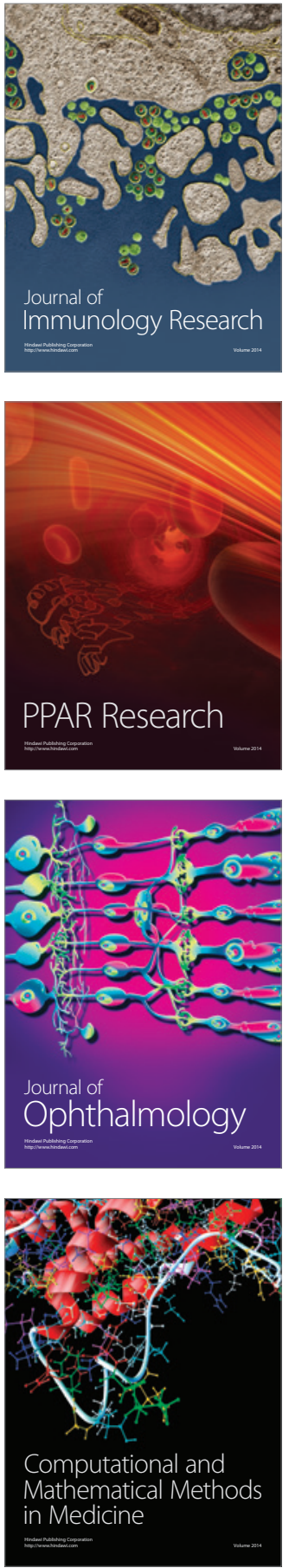

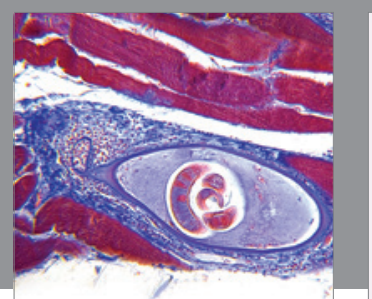

Gastroenterology Research and Practice

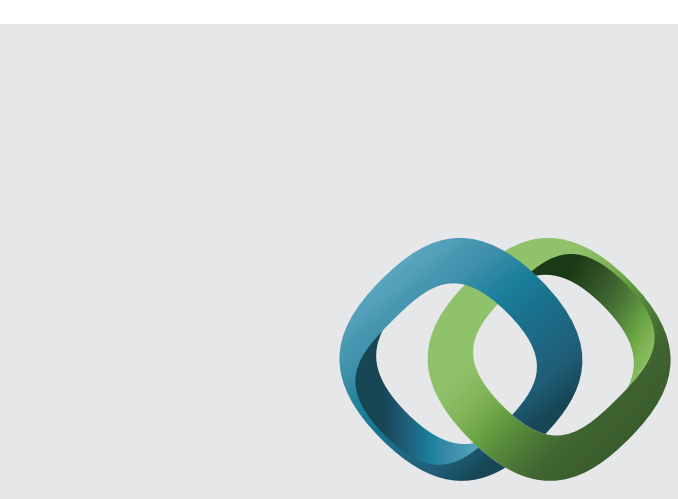

\section{Hindawi}

Submit your manuscripts at

http://www.hindawi.com
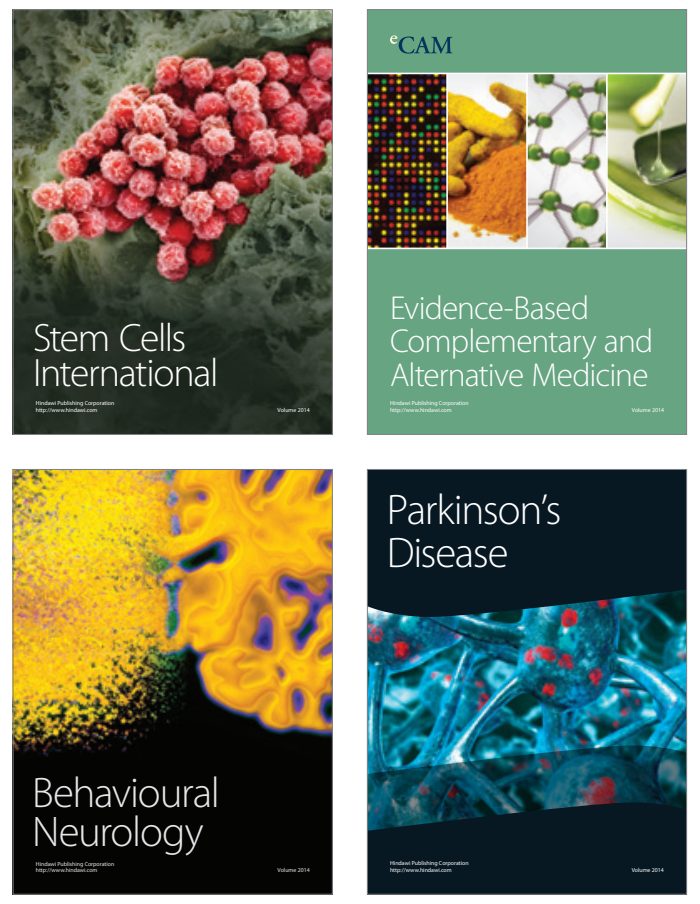
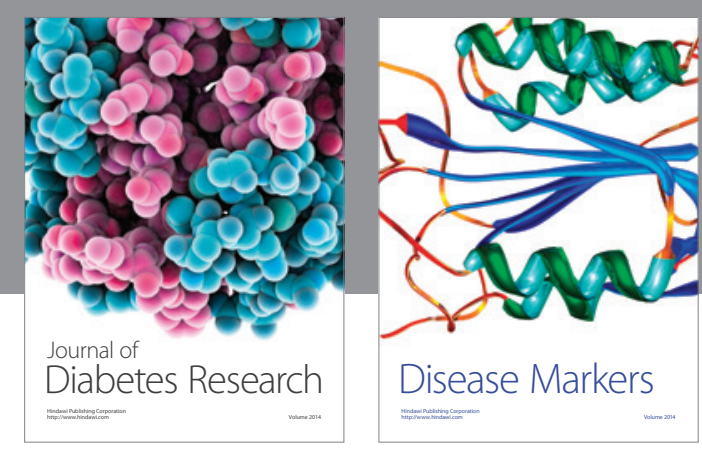

Disease Markers
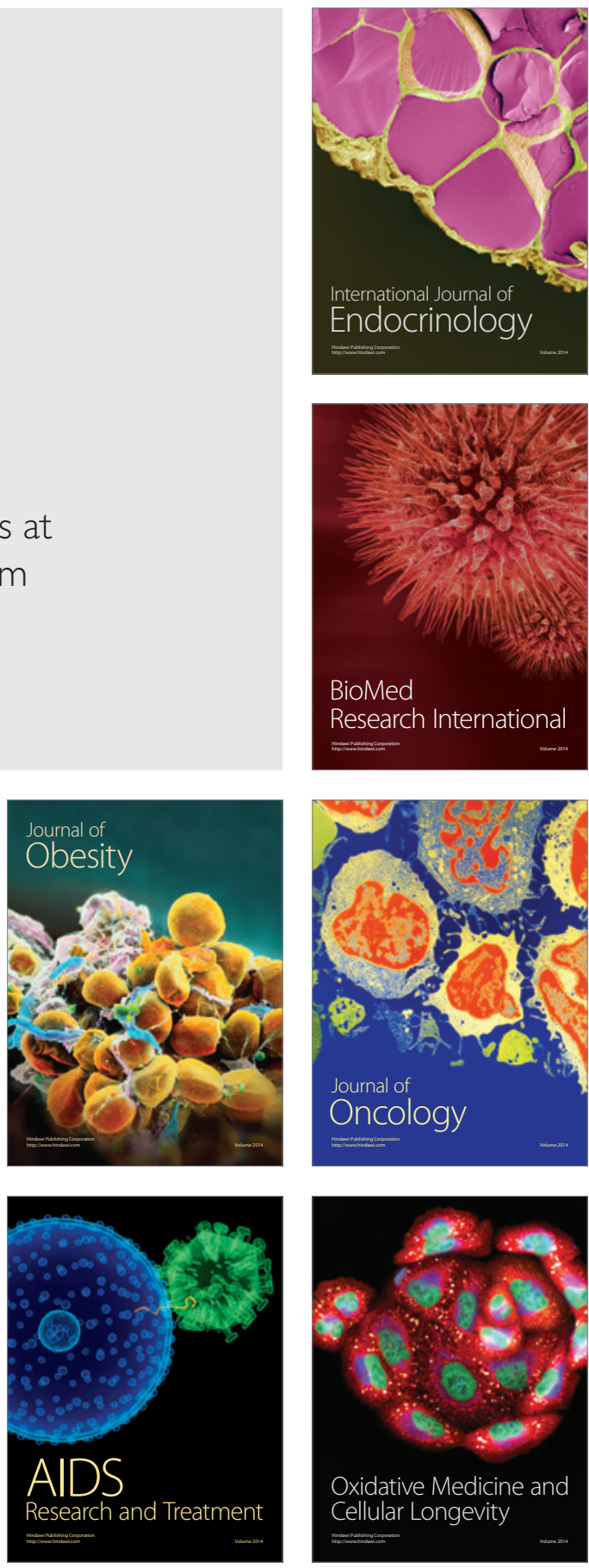